JEL Classification: G11, G12, G15

Keywords: country risk, sovereign risk, political risk, currency risk, banking sector risk, economic risk, country asset allocation, country selection strategies, return predictability, international asset pricing, crosssection of returns, international diversification

\title{
Country Risk and Expected Returns Across Global Equity Markets*
}

Adam ZAREMBA - Dubai Business School, University of Dubai, UAE; Department of Investment and Capital Markets, Poznań University of Economics and Business, Poland, (adam.zaremba@ue.poznan.pl)

\section{Abstract}

Assessing and pricing country risk poses a considerable challenge to tactical asset allocation across national equity markets. This research examines the relationship between the country composite risk (together with its component risks related to sovereign credit, currency, banking sector, economic structure, and political situation) and expected returns, also identifying general implications for international investors. An equal-weighted portfolio of risky countries outperforms safe countries by approximately 0.50 percentage points per month. The application of this cross-sectional pattern, however, still poses a significant challenge for investment practice. The abnormal performance proves insignificant for capitalization-weighted and liquidity-weighted portfolios as well as within the subgroups of the full sample. Also, we observe that the profitability of the risk-based strategies has disappeared in the years following the global financial crisis.

\section{Introduction}

Measuring risk exposure in across country equity markets poses a considerable challenge. On the one hand, the traditional risk measures (i.e., beta, standard deviation, idiosyncratic volatility, or value at risk) have not yet been empirically proven to be clearly related to the expected returns (Umutlu, 2015; Zaremba, 2015a). On the other hand, international investors face other risks and "shocks" such as risks of expropriation, currency devaluation, coups, or regulatory changes (Bekaert et al., 1996; Dahlquist \& Bansal, 2002). These risks currently seem particularly relevant due to recent events: the global financial turmoil forced governments to seize the assets of its citizens, and military conflicts and political instability spread across numerous countries in Africa, Europe, and the Middle East.

In this paper, we aim to examine the pricing of various risks - specifically those related to sovereign credit, economic structure, politics, banking sector, and currency - in the global financial markets, and to test the implications of this pricing for international stock market investors. Thus, the major target of this study is to explore the relationship between various dimensions of country risk and expected returns in country equity markets. In particular, we intend to examine whether this relationship could be translated into a profitable country selection strategy.

In this research, we rely on sorting and time-series tests. We form portfolios and assess their performance with asset pricing models, testing for abnormal returns and

\footnotetext{
*We thank the anonymous referees for insightful comments that benefited the paper. This study is a part of project no. UMO-2014/15/D/HS4/01235 financed by the National Science Centre of Poland.
} 
monotonic relations. Furthermore, we conduct a battery of robustness tests to align our outcomes with investment practice.

This paper contributes in two ways. First, we provide new comprehensive out-ofsample evidence on pricing various risks in international financial markets. Several authors indicate that financial, political, and economic risks are priced at the country level (i.e., riskier countries are associated with higher expected returns) (Ferson et al., 1995; Erb et al., 1995, 1996; Andrade, 2009; Dahlquist \& Bansal, 2002; Bekaert et al., 1996; Harvey, 2004; Dimic et al., 2015). In contrast to the prior studies, we use the risk indices of the Economist Intelligence Unit (EIU) which are widely available to investors via popular financial databases - such as Bloomberg - and examine their influence on returns using fresh data from the years 1999-2015. ${ }^{1}$ We consider six categories of risk related to sovereign debt, banking sector, economic structure, currency, politics, and economic structure, and test their importance within a broad set of 75 country equity markets from developed, emerging, and frontier markets. None of the earlier studies used this measure of risk, and our sample is significantly broader and more recent than previous studies. For example, the 2015 paper by Dimic et al. (2015) relies on returns from 64 countries for a period ending in 2013.

Second, our other motivation is also purely practical. The earlier research focused almost exclusively on asset pricing with the use of cross-sectional tests (e.g., Ferson et al., 1995; Erb et al., 1995, 1996; Andrade, 2009; Dahlquist \& Bansal, 2002; Bekaert et al., 1996; Harvey, 2004; Dimic et al., 2015), largely ignoring its practical applicability for international investors. In contrast, in this paper we examine whether the cross-sectional return patterns could be used in cross-national asset allocation. Our study relies on a more realistic portfolio approach that was not utilized in earlier studies, although it represents an investors' standpoint much better.

This second contribution is related to the structural changes that have occurred in international equity markets. Recent years brought a rapid growth of passive investment products (e.g., futures markets and exchange-traded funds [ETFs]), which provide easy access to international markets covered by country indices. Considering the abundant opportunities and the large size of the global markets, investment tools available for country-level asset allocation still appear relatively modest. Stock-level investors have at their disposal ample literature addressing cross-sectional and time-series return predictive signals. In the field of passive ETFs and index products, such tools largely remain to be developed and are confined to the basic phenomena of value (Macedo, 1995; Asness et al., 1997; Desrosiers et al., 2004; Angelidis \& Tessaromatis, 2014; Zaremba, 2015b), size (Keppler \& Traub, 1993; Asness et al., 1997; Keppler \& Encinosa, 2011), momentum (Asness et al., 1997, Bhojraj \& Swaminathan, 2006; Balvers \& Wu, 2006), and quality (Zaremba, 2015c). None of these studies adopts the country risk as the basis for portfolio formation. Thus, by testing the relationship between country risk and future returns, we try to broaden the set of tools available for investors. Consequently, in this paper, we attempt to use a more practical approach in comparison to earlier studies.

Our main findings could be summarized as follows. The country-level expected returns are significantly related to country risk. In the years 1999-2015, the equal-

${ }^{1}$ A review and comparison of country risk measures are provided by Erb et al. (1996) and Hoti and McAleer (2002, 2005). 
weighted portfolios of the riskiest countries outperformed the safest countries by approximately $0.50 \%$ on a monthly basis. The risk-return relationship was most pronounced for the sovereign, economic structure, and banking sector risks. However, the risk-based country asset allocation is not very robust to real-life constraints. These strategies worked only for equal-weighted portfolios, and therefore require allocation of considerable parts of the portfolio to small and illiquid markets. Furthermore, the strategies required country picking from a very broad country set and did not prove profitable within smaller subsamples of developed countries only. Finally, the performance of risk-based strategies seriously deteriorated in the period following the global financial crisis, effectively turning into negative territory.

The rest of the paper is organized as follows. The next section presents the data sources and methods employed in this research. Then, we report and discuss our empirical results. Finally, the last section concludes the paper.

\section{Data and Methods}

In this study, we examine the performance of country-level investment strategies based on country risk measures. We construct various portfolios from sorts on risk and examine their performance with asset-pricing models.

In this section, we describe first the data sources and the research sample. Next, we discuss the portfolio construction procedures and the asset pricing models. Finally, we present the range of robustness checks applied in this study.

\subsection{Data Sources and Sample Description}

This research is based on the returns of international stock market indices from 75 countries. $^{2}$ The sample includes both existing and discontinued indices (e.g., MSCI Venezuela) to avoid survivorship bias. All source data was obtained from the Bloomberg database. We use monthly time-series as they provide a sufficient number of observations to ensure the effectiveness of the tests performed and prevent excessive exposure to microstructure issues (de Moor \& Sercu, 2013). To maintain the consistency of return computation methodology, we adopted MSCI indices for the countries in this study. ${ }^{3}$ Where an MSCI index was unavailable for the given country,

\footnotetext{
2 Argentina, Australia, Austria, Bahrain, Bangladesh, Belgium, Brazil, Bulgaria, Canada, Chile, China, Colombia, Croatia, Cyprus, the Czech Republic, Denmark, Egypt, Estonia, Finland, France, Germany, Greece, Hong Kong, Hungary, India, Indonesia, Ireland, Israel, Italy, Japan, Jordan, Kazakhstan, Kenya, Kuwait, Latvia, Lebanon, Lithuania, Malaysia, Mexico, Morocco, Mauritius, the Netherlands, New Zealand, Nigeria, Norway, Oman, Pakistan, Peru, the Philippines, Poland, Portugal, Qatar, Romania, Russia, Serbia, Saudi Arabia, Singapore, Slovenia, South Africa, South Korea, Spain, Sri Lanka, Sweden, Switzerland, Taiwan, Thailand, Trinidad and Tobago, Tunisia, Turkey, Ukraine, the United Arab Emirates, the United Kingdom, the United States, Venezuela, and Vietnam. Generally, we aim to use the broadest possible set of countries that meet two basic conditions: a) they are covered by the EIU, and b) one of the major index providers (MSCI, Dow Jones, or Stoxx) calculates value-weighted indices, using both gross and net approaches, that are available in popular financial databases (e.g., Bloomberg).

${ }^{3}$ The decision to adopt MSCI indices is also aimed at aligning this research with investment practice. These indices are constructed and managed with the intention of being fully investable from the perspective of an international institutional investor (MSCI, 2015a), and cover approximately $85 \%$ of stock market capitalization in the countries they represent (MSCI, 2015b). The MSCI indices represent capitalizationweighted benchmarks that are commonly tracked worldwide. Moreover, they constitute the basis for numerous futures contracts and over 650 exchange traded funds worldwide (https://www.msci.com/indexes).
} 
our second choice was the Dow Jones index, and the third, STOXX. The basic characteristics of the research sample are displayed in Table A1 in the Appendix.

Returns are calculated based on capitalization-weighted total return indices (i.e., indices adjusted for corporate actions and cash distributions to investors). The sample period runs from December 1998 to June 2015, as available (198 monthly observations). A stock market index is included in the sample in month $t$ when it is possible to compute its gross and net returns in month $t$, the appropriate weighting factor (i.e., capitalization or turnover) at the end of month $t-1$, and its country risk indicator at the end of month $t-1$. The initial index values and capitalizations were collected in local currencies. Subsequently, all data was denominated in U.S. dollars to obtain a pooled international sample. ${ }^{4}$ To ensure consistency with the USD approach, excess returns are computed over returns on the Bloomberg generic U.S. 3month T-Bill.

As a proxy for country risk, we use the EIU indicators calculated by its Country Risk Service (EIU, 2015a). These indices (referred to here as EIU indices) continuously monitor the condition of 128 emerging and developed countries and are among the most respected and commonly used risk metrics (Hoti \& McAleer, 2002, 2005). The EIU have been computed since 1997 and are the only recognized risk indices available free in Bloomberg. This approach additionally aligns our research with both the perspective and investment practices of the institutional investor. Based on more than 60 qualitative and quantitative indicators, the EIU provides a rating for each of the countries on a 100-point scale in five distinct areas (EIU, 2015b):

(1) Sovereign risk measures the risk of a build-up in arrears of principal or interest on foreign or local-currency debt that is a direct obligation or guarantee of the sovereign.

(2) Currency risk measures the risk of devaluation of the local currency with respect to the reference curency (usually the U.S. dollar or euro) of $25 \%$ or more in nominal terms during the next 12-month period.

(3) Banking sector risk gauges the risk of a systemic crisis wherein banks holding $10 \%$ or more of total bank assets become insolvent and unable to discharge their obligations to depositors or creditors.

(4) Political risk evaluates a range of political factors relating to political stability and effectiveness that could affect a country's ability and commitment to service its debt obligations or cause turbulence in the foreign-exchange market. This rating also informs the first three areas.

(5) Economic structure risk is derived from a series of macroeconomic variables of a structural (non-cyclical) nature. Consequently, the rating for economic structure risk tends to be relatively stable, evolving in line with the structural changes in the economy.

Finally, the overall country risk measure is a simple score combining the sovereign, currency, and banking sector risks.

\footnotetext{
${ }^{4}$ According to Liew and Vassalou (2000) or Bali et al. (2013), comparisons using different currency units may be misleading. This is particularly important in relation to the emerging and frontier markets in which inflation and risk-free rates are occasionally very high and differ significantly across markets. The approach to convert all data into a single currency is also employed, for example, by Bekaert et al. (2007) and Brown et al. (2008).
} 


\subsection{Portfolio Construction and Performance Evaluation}

Based on the six risk indicators presented above, we form portfolios using a uniform procedure. To this end, the stock market indices are ranked on the current value of a given risk metric at the end of each month $t-1$. Next, the indices grouped within tertiles (i.e., low-risk, middle-risk, and high-risk countries) are used to form equal-weighted portfolios. Finally, the differential portfolios (i.e., the zero-investment portfolios) are built based on the market extremes; these are effectively dollar-neutral long-short portfolios. We consistently adopt a long (short) position in the tertile portfolio of countries with the highest (lowest) risk metrics. The aim of building the zero-investment portfolios is to compare the returns on the most and the least risky countries.

To align with the perspective of an international investor - motivated to invest in foreign index-based instruments, such as ETFs or futures contracts-we examine the risk-based portfolios by adopting cross-sectional asset pricing models derived from the country-level data. We use two distinct models. The first model is the cross-country equivalent of the capital asset pricing model, abbreviated CAPM (Sharpe, 1964). According to the CAPM, asset returns depend solely on the market portfolio as described by the following regression:

$$
\mathrm{R}_{\mathrm{i}, \mathrm{t}}=\alpha_{\mathrm{i}}+\mathrm{R}_{\mathrm{f}, \mathrm{t}}+\beta_{\mathrm{rm}, \mathrm{i}} \cdot\left(\mathrm{R}_{\mathrm{mt}}-\mathrm{R}_{\mathrm{f}, \mathrm{t}}\right)+\varepsilon_{\mathrm{i}, \mathrm{t}}
$$

where $R_{i, t}, R_{m, t}$ and $R_{f, t}$ are returns on the analyzed asset $i$, market portfolio and riskfree returns, respectively, at time $t$, and $\alpha_{i}$ and $\beta_{r m, i}$ are regression parameters. The $\alpha_{i}$ intercept (Jensen's alpha) measures the average abnormal return. The risk-free rate is, again, the one-month benchmark U.S. T-Bill rate. In this approach, the return on the market risk factor $(M k t R f)$ is calculated as an excess return over the risk-free rate of a capitalization-weighted portfolio formed from all country indices in the sample.

The second model is the country-level four-factor model. The model is identical to the four-factor model introduced by Carhart (1997), but all the asset-pricing factors are estimated based on returns on MSCI stock market indices:

$$
\begin{aligned}
\mathrm{R}_{\mathrm{i}, \mathrm{t}}=\alpha_{\mathrm{i}}+\mathrm{R}_{\mathrm{f}, \mathrm{t}}+ & \beta_{\mathrm{rm}, \mathrm{i}} \cdot\left(\mathrm{R}_{\mathrm{m}, \mathrm{t}}-\mathrm{R}_{\mathrm{f}, \mathrm{t}}\right)+\beta_{\mathrm{SMB}, \mathrm{i}} \cdot \mathrm{SMB}_{\mathrm{t}}+\beta_{\mathrm{HML}, \mathrm{i}} \cdot \mathrm{HML}_{\mathrm{t}} \\
& +\beta_{\mathrm{WML}, \mathrm{i}} \cdot \mathrm{WML}_{\mathrm{t}}+\varepsilon_{\mathrm{i}, \mathrm{t}}
\end{aligned}
$$

where $\beta_{r m, i}, \beta_{S M B, i}, \beta_{H M L, i}, \beta_{W M L, i}$, and $\alpha_{i}$ are the model estimated parameters; and $\beta_{r m, i}$ is analogous, but not equal, to the CAPM beta. $\beta_{S M B, i}, \beta_{H M L, i}, \beta_{W M L, i}$, are measures of exposure to the $S M B_{t}$ (small minus big), $H M L_{t}$ (high minus low), and $W M L_{t}$ (winners minus losers) risk factors, respectively, which are defined as the returns on the zero-cost arbitrage portfolios. $S M B_{t}$ is the difference in returns on diversified portfolios between small and large markets at time $t$ while $H M L_{t}$ is, in general, the difference between returns on portfolios of diversified value (high book-to-market) and growth (low book-to-market) markets. Finally, $W M L_{t}$ covers momentum returns measured by returns on the so-called winner and loser portfolios which were used in the initial studies on this anomaly (Jegadeesh \& Titman, 1993). The $W M L_{t}$ denotes the 
difference between returns on the diversified winner and loser portfolios in the preceding year. In other words, $S M B_{t}, H M L_{t}$, and $W M L_{t}$ returns on zero-cost marketneutral long or short portfolios formed based on size, value, and momentum characteristics. All the factor returns are based on the index-level data. In consequence, the model tests whether the inclusion of a given portfolio expands the frontier of an international index investor with an exposure to country-level market, value, size and momentum anomalies. ${ }^{5}$ We discuss the detailed factor implementation procedures in Table 3 in the Appendix.

Following Fama and French (2012), all regression parameters are estimated using OLS regressions. ${ }^{6}$ This complies with the remarks of Cochrane (2005), who regards this method as usually more robust than, for example, generalized least squares (GLS). To determine whether the intercepts in a group of portfolios statistically differ from 0 , they were evaluated with the common GRS test statistic, as Gibbons et al. (1989) suggests:

$$
\begin{aligned}
G R S=\left(\frac{T}{N}\right) \times\left(\frac{T-N-L}{T-L-1}\right) \times \hat{\alpha}^{\prime \mathbb{\mathcal { L }}^{-1} \widehat{\alpha}} & \\
& \quad \times\left[1+E_{T}(f)^{\prime} \hat{\Omega}^{-1} E_{T}(f)\right]^{-1} \sim F_{N, T-N-K}
\end{aligned}
$$

where $T$ is the length of the time-series (sample size), $N$ is the number of portfolios to be explained in the examined group, and $L$ denotes the number of explanatory factors. $E_{T}(f)$ is a vector of expected returns on asset pricing factors (estimated as a simple average over the investigated period; see Cochrane, 2005, p. 231), $\hat{\Omega}$ is the covariance matrix of the asset pricing factors, $\hat{\alpha}$ is the vector of regression intercepts, and $\hat{\Sigma}$ is the residual covariance matrix for the sample. The test's critical values are obtained from Fisher's distribution with $N$ and $T-N-L$ degrees of freedom. The null hypothesis is that all the intercepts (five) are equal to 0 .

One of the weaknesses of the GRS test statistic is that it simply indicates that some of the portfolios in a given set significantly outperform, but does not consider the structure or monotonicity. Therefore, to test whether the excess returns (intercepts) are systematically increasing or decreasing with the changes in the underlying variable, we also carry out a monotonic relation (MR) test introduced by Patton and Timmermann (2010). This is a simulation-based test, where the null hypothesis says that there is no monotonic pattern in returns. The MR test uses a bootstrap approach in which the monthly returns (raw or risk-adjusted) are randomly drawn with replacements from the original time-series sample. We perform 30,000 random draws, effectively generating 30,000 time-series of returns for each of the investigated portfolios. Next, we calculate the mean excess returns for each time-series and de-mean them by subtracting the original portfolios' time-series averages. Finally, we examine the null hypothesis that there is a flat pattern across the risk-sorted portfolios (no cross-sectional differences) against the alternative hypothesis that there is an increasing monotonicity related to the

\footnotetext{
${ }^{5}$ These three effects have so far been documented across country equity indices: size, by Keppler and Traub (1993) and Keppler and Encinosa (2011); value, by Macedo (1995), Kim (2012), and Angelidis and Tessaromatis (2014); and momentum, by Balvers and Wu (2006) and Bhojraj and Swaminathan (2006).

${ }^{6} \mathrm{We}$ calculated portfolio returns based on arithmetic rates of return, but we subsequently transformed them to $\log$-returns for the purpose of statistical analysis. All the results presented in Tables 1-9 are expressed in $\log$-returns. Furthermore, the models' parameters with corresponding $t$-statistics are always based on the Newey-West estimator (Newey and West, 1987).
} 
risk indicator. In order to do this, we compute the return differences between adjacent portfolios: $\Delta_{i}=r_{t, i}-r_{t, i-1}$. The basic hypothesis is:

$$
H_{0}: \Delta=0 \quad \text { vs } \quad H_{1}: \min _{i=1,2 \ldots, n} \Delta_{i}>0
$$

The test statistic is given by:

$$
J_{T}=\min _{i=1,2 \ldots, n} \hat{\Delta}_{i}
$$

for the original sample. To obtain the $p$-value, it is sufficient to count the number of cases in which $J_{T}<J_{T}^{b}$, where, for the de-meaned bootstrap draws, $J_{T}^{b}$ is computed analogously to $J_{T}$ and then divided by the number of bootstraps $(30,000)$. We implement the test for both raw returns and factor model-adjusted returns, according to the approach detailed in Patton and Timmermann (2010).

\subsection{Robustness Tests}

In order to verify the results of the research, we perform a battery of robustness checks.

Adjustment for taxes on dividends. The majority of country-level studies are based on gross returns (i.e., without adjustment for any capital gains taxes). This reflects the standpoint of an institutional investor capable of avoiding taxes on dividends that vary from country to country. Nonetheless, many individual and even institutional investors are unable to neutralize entirely the impact of dividend taxes. As a result, in addition to the standard "gross" return convention, we also apply the alternative "net" approach in which dividends are calculated on an after-tax basis. This approach controls for different tax rates on dividends in various countries. ${ }^{7}$

Alternative weighting schemes. When forming anomaly-based portfolios, we examine the three distinct weighting schemes. We start with the equal-weighting approach, which is the common practice in country-level studies (e.g., Asness et al., 2013) and aptly reflects the opportunities of investing in the liquid futures or ETF markets. Nonetheless, it overestimates the importance of small and illiquid markets and might be distorted by the returns on rebalancing (Willenbrock, 2011). Therefore, we supplement our research with capitalization-weighted and liquidity-weighted portfolios. In the latter approach, we use the cumulative turnover in months $t-12$ to $t-1$ as the proxy for liquidity. The main drawback of these alternative approaches is the risk of the results being excessively dominated by the largest and most liquid equity markets.

\footnotetext{
7 The treatment of dividends and taxes on dividends in short sale transactions varies across countries and across time. Thus, the returns on the zero-investment portfolios in the net approach should be essentially regarded as returns on differential portfolios that accentuate the outperformance of the top portfolios over the bottom portfolios.
} 
Alternative currency approaches. The basic study presents the investments denominated in U.S. dollars. Nevertheless, we re-examine all the computations using the euro and Japanese yen. We found no qualitative differences, so for brevity, we report none of these outcomes.

Alternative breakpoints. In addition to the tertile approach, we re-examine the risk-based strategies with a quintile approach. These portfolios are less diversified and thus more volatile.

Performance in sub-periods. We also examine portfolio performance within various subsets of the main sample and in alternative market states. Thus, we divide the research period into two halves: before and after March 31, 2007. To avoid the effect of an arbitrary cut-off date, we use two additional dates related to important market events: the Dow Jones peak on October 11, 2007, and the Lehman Brothers bankruptcy on September 16, 2008. Finally, we investigate the returns in bull and bear markets (i.e., in months when the market portfolio returns turn either positive or negative).

The impact of various market conditions. Following the intuition of Jacobs (2015), we investigate whether the risk-based portfolios perform equally in periods of different limits on arbitrage (i.e., in times of high and low volatility, market liquidity, credit risk, and term spread). We employ representative metrics and re-examine the portfolio performance within the subsamples where the metrics at the end month $t-1$ vary from their medians. As the representation of the general liquidity, the 3-month USD TED spread is employed, which is the difference between the 3-month USD LIBOR rate and the yield on the U.S. benchmark 3-month T-bill. The expected market volatility is represented by the VIX volatility index, a popular measurement of the implied volatility of index options. The BBB spread of U.S. 10-year corporate bonds over 10-year benchmark treasury bonds is the proxy for the credit risk. Finally, the term-spread risk is used to represent the difference between the yields of 10- and 2year benchmark U.S. treasury bonds.

The impact of investor sentiment. We also research the returns on the strategies during times of high and low investor sentiment by calculating the mean returns for any month $t$ where a given investor sentiment indicator differs from the median at the end of month $t-1$. We use four different sentiment measurements: the market-level investor sentiment index of Baker and Wurgler (2006) (BW), ${ }^{8}$ the State Street Investor Confidence Index (SSIC), ${ }^{9}$ the Sentix Economic Indices Global Aggregate Overall Index (Sentix), ${ }^{10}$ and the Weighted Manufacturing and NonManufacturing Composite Purchasing Managers' Index (PMI). ${ }^{11}$

Subsamples of the examined countries. We form an array of double-sorted portfolios and test their performance in the same way as for the single sorted portfolios. Initially, we sort markets on additional variables, then we divide the sample in two halves based the median value of a given variable and test the strategies within the

\footnotetext{
${ }^{8}$ The data on the BW index (sourced from http://people.stern.nyu.edu/jwurgler/) are only available for the period ending December 2010. As a result, in the case of this metric, our analysis is based on the shortened study period.

${ }^{9} \mathrm{Http}: / /$ www.statestreet.com/ideas/investor-confidence-index.html (accessed 20 September 2015).

${ }^{10} \mathrm{Https}: / /$ www.sentix.de/index.php/en/sentix-Economic-News (accessed 20 September 2015).

${ }^{11} \mathrm{Https} / / / \mathrm{www} \cdot \mathrm{markit} . \mathrm{com} /$ product/pmi,

https://www.instituteforsupplymanagement.org/ismreport/mfgrob.cfm (accessed 20 September 2015).
} 
specific subsets of the entire sample. In this approach, due to a relatively small number of constituents of the portfolios from double sorts, we rely on the capitalizationweighting scheme. We use a range of additional sorting variables: stock market capitalization, stock market liquidity (cumulative turnover in months $t-12$ to $t-1$ ), bookto-market $(\mathrm{B} / \mathrm{M})$ ratios (lagged 4 months to avoid look-ahead bias), and past performance (cumulative return in months $t-12$ to $t$-1). Furthermore, we investigate the performance within open (O) and closed (C) markets. For each month, we sort countries based on their KAOPEN indices (Chinn \& Ito, 2008)-measuring the country's de jure degree of capital account openness. Finally, following Malin and Bornhold (2013) and Kim (2012), we examine the returns within both developed and emerging markets. We dynamically follow the MSCI Market Classification Framework with all the classification changes over the period. ${ }^{12}$ The developed markets subset in a given month contains the developed markets according to the MSCI classification, whereas the "emerging" category encompasses all the remaining markets: emerging, frontier or standalone.

\section{Results}

In this section, we first report on the performance of the simple equal-weighted portfolios from the sorts on country risk and its individual components. Subsequently, we present the results of a series of robustness checks aimed at aligning the analysis with investment practice.

\subsection{Performance of Risk-Based Country Selection Strategies}

Our initial analysis clearly confirms the relationship between the country risk and future returns on a local equity market index, consistent with the earlier findings of Bekaert et al. (1996), Dahlquist and Bansal (2002), Harvey (2004), and Andrade (2009). Table 1 reports the links between returns and the aggregate country risk. In the gross-return approach, the mean monthly return on the riskiest tertile of countries amounts to $0.89 \%$, and to only $0.39 \%$ on the safest tertile. The mean monthly return on the zero-investment portfolio equals $0.48 \%$ and departs from 0 by 2.1 standard deviations. The null hypothesis of the test of monotonic relation applied to the raw excess returns is rejected. In other words, we report a significant cross-sectional pattern in raw returns related to the country risk - the riskier the country, the higher the returns. Furthermore, the riskier countries are insignificantly more volatile than the safe countries. The standard deviation of monthly returns equals $6.05 \%$ for the riskiest countries and $5.39 \%$ for the safest. As a result, the risky markets have Sharpe ratios more than twice as high as the safe ones.

\footnotetext{
${ }^{12}$ See http://www.msci.com/products/indexes/market_classification.html (accessed 14 March 2015).
} 
Table 1 The Performance of Equal-Weighted Tertile Portfolios from Sorts on Country Risk

\begin{tabular}{|c|c|c|c|c|c|c|c|c|c|c|c|c|}
\hline & Low & Medium & High & $H-L$ & $M R$ & GRS & Low & Medium & High & $H-L$ & $M R$ & GRS \\
\hline & \multicolumn{6}{|c|}{ Gross returns } & \multicolumn{6}{|c|}{ Net returns } \\
\hline \multirow[t]{2}{*}{ Mean } & 0.39 & 0.75 & $0.89^{\star \star}$ & $0.48^{\star \star}$ & 2.5 & & 0.34 & 0.68 & $0.88^{\star \star}$ & $0.53^{\star \star}$ & 0.4 & \\
\hline & $(1.08)$ & (1.62) & $(1.99)$ & $(2.10)$ & & & (0.94) & $(1.50)$ & (2.03) & $(2.28)$ & & \\
\hline Volatility & 5.39 & 6.02 & 6.05 & 3.20 & & & 5.47 & 5.86 & 5.98 & 3.16 & & \\
\hline SR & 0.25 & 0.43 & 0.51 & 0.52 & & & 0.21 & 0.40 & 0.51 & 0.58 & & \\
\hline Skewness & -1.18 & -1.16 & -1.00 & 0.12 & & & -1.27 & -1.13 & -0.97 & 0.10 & & \\
\hline Kurtosis & 4.27 & 4.58 & 5.27 & 1.14 & & & 4.70 & 4.20 & 5.21 & 0.93 & & \\
\hline \multirow[t]{2}{*}{$\alpha$ CAPM } & 0.13 & $0.47^{\star \star}$ & $0.63^{\star *}$ & $0.49^{\star \star}$ & 1.3 & 5.4 & 0.15 & $0.48^{\star \star}$ & $0.70^{\star \star \star}$ & $0.53^{\star \star}$ & 0.3 & 2.0 \\
\hline & (0.95) & (2.36) & (2.48) & (2.17) & & & $(1.07)$ & $(2.55)$ & $(2.80)$ & (2.42) & & \\
\hline \multirow[t]{2}{*}{$\alpha_{4 F}$} & 0.01 & 0.21 & 0.30 & 0.27 & 23.5 & 28.9 & 0.02 & $0.26^{\star}$ & $0.39^{\star \star}$ & 0.34 & 14.5 & 10.5 \\
\hline & $(0.08)$ & (1.33) & (1.57) & (1.31) & & & $(0.19)$ & $(1.68)$ & (1.99) & (1.63) & & \\
\hline
\end{tabular}

Notes: The table presents the performance of equal-weighted tertile portfolios from sorts on composite country risk. $\mathrm{H}-\mathrm{L}$ is the zero-investment portfolio that includes a long position in the high-risk portfolio and a short position in the low-risk portfolio. Mean is the mean monthly excess return; Volatility is the standard deviation of monthly returns; $S R$ is the annualized Sharpe ratio, and $\alpha_{C A P M}$ and $\alpha_{4 F}$ are intercepts from the country-level CAPM and four-factor model, respectively. "Gross" and "net" approaches refer to whether adjustment is made for taxes on dividends (net approach) or not (gross approach). MR and GRS are $p$ values from the tests of monotonic relation by Patton and Timmerman (2010) and the GRS test, (Gibbons et al., 1989), respectively. The means, volatilities, $p$-values, and intercepts are expressed in percentage terms. The numbers in brackets are $t$-statistics based on bootstrap standard errors, and values showing statistical significance at the $10 \%$ level are given in bold type. Asterisks $\left({ }^{*},{ }^{* *},{ }^{* * *}\right)$ indicate values significantly different from zero at the $10 \%, 5 \%$, and $1 \%$ levels, respectively.

Country risk remains a strong influence even after adjusting for the market risk, in line with the CAPM. The monthly intercept on the dollar-neutral portfolio equals $0.49 \%$ (i.e., it is positive and significantly different from 0). Furthermore, the null hypotheses in both the GRS and MR tests are rejected, indicating true abnormal returns and monotonicity in abnormal returns with respect to the CAPM, respectively.

Interestingly, the abnormal returns are fully explained with the four-factor model, which accounts for the value, size, and momentum anomalies at the country level. The returns on the risk-based portfolios are no longer significantly abnormal, and neither the GRS test nor the MR test are rejected. The four-factor model entirely explains the cross-sectional variation in returns related to the country risk. Initially, this phenomenon corresponds with the findings of Erb et al. (1996), who identify a positive correlation of index valuation ratios (e.g., book-to-market ratio, earnings-toprice ratio, cash-flow-to-price ratio, and dividend yield) with the country risk. Nonetheless, our sample displays quite a different pattern. Figure 1 presents the average risk ratings within the subgroups of small, large, growth, value, up, and down markets. The largest dispersion among the risk ratings is visible when sorting on size (Figure 1, Panel A): smaller countries are, historically, systematically riskier than larger ones. Thus, the country-risk is closely related to the "small-country effect" documented by Keppler and Traub (1993) and Keppler and Encinosa (2011), which is reflected in the $S M B$ portfolio of the four-factor model. 


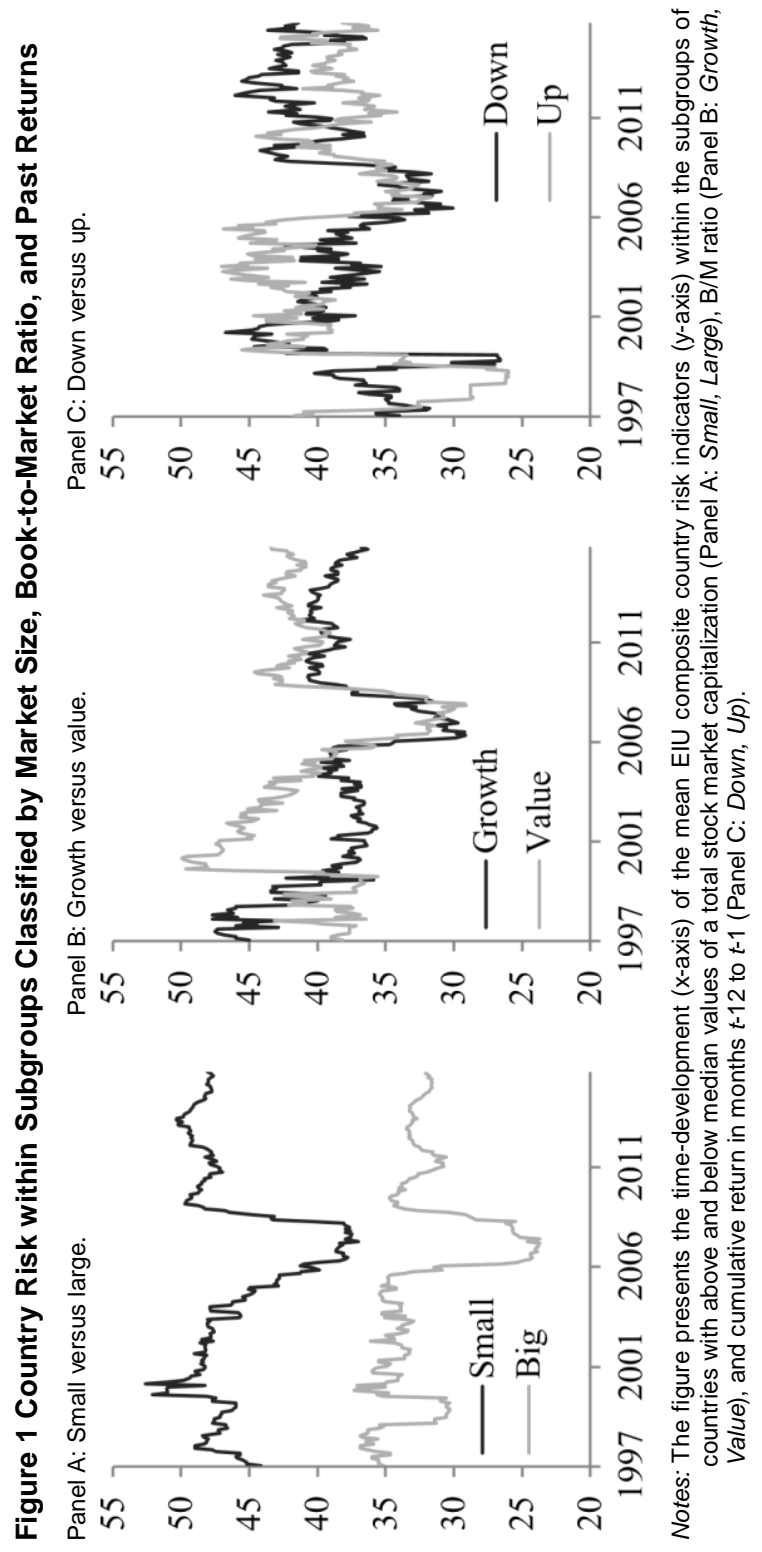


The outcomes of the equal-weighted tertile portfolios formed on risk in the netreturn approach correspond to those of the gross return approach. Effectively, there are no qualitative differences. The outperformance of the risky markets over the safe ones is slightly greater than with the gross approach. The mean monthly return and the intercept from the CAPM on the zero-investment portfolio both equal $0.53 \%$. Also, both values are significantly different from zero, with the overperformance confirmed by the MR and GRS tests. None of the tests, however, detect any cross-sectional pattern in the intercepts from the four-factor model, despite the positive and significant alpha in the riskiest portfolio.

Following the motivation of Erb et al. (1996), we adhered to a detailed examination of the component risks of the aggregate country metrics: sovereign, currency, banking sector, political, and economic structure risks. First, although the individual metrics largely rely on different underlying indicators, they rank the countries similarly: the mean cross-sectional correlation between country rankings based on various types of risks ranges between 0.78 and 0.97 (Table 2). In other words, irrespective of the risk category used to form country rankings, the resulting quintile portfolios remain relatively similar.

Table 2 Mean Pair-Wise Correlation Coefficients Among the Country Risk Indicators

\begin{tabular}{|c|c|c|c|c|c|c|c|c|c|c|}
\hline & \multicolumn{5}{|c|}{ Correlation coefficients } & \multicolumn{5}{|c|}{ t-stats } \\
\hline & \multicolumn{5}{|c|}{ Currency Banking Political Economic Country } & \multicolumn{5}{|c|}{ Currency Banking Political Economic Country } \\
\hline Sovereign & 0.94 & 0.90 & 0.83 & 0.91 & 0.97 & 23.89 & 17.01 & 12.23 & 18.43 & 35.62 \\
\hline Currency & & 0.92 & 0.78 & 0.87 & 0.79 & & 20.24 & 10.37 & 14.46 & 11.30 \\
\hline Banking & & & 0.87 & 0.87 & 0.97 & & & 14.02 & 13.97 & 30.99 \\
\hline Political & & & & 0.80 & 0.85 & & & & 11.04 & 13.33 \\
\hline Economic & & & & & 0.91 & & & & & 17.57 \\
\hline
\end{tabular}

Notes: The table presents mean pair-wise Pearson's correlation coefficients between the cross-sectional rankings by EIU indicators of sovereign risk, currency risk, banking sector risk, political risk, economic structure risk, and composite country risk. The table also reports the corresponding $t$-statistics.

Table 3 informs on the performance of the equal-weighted portfolios from sorts on individual risk measures. Three of the five risk measures, reported in Table 4, prove to be a reliable basis for portfolio formation. The zero-investment portfolios from sorts on sovereign, banking sector, and economic structure risks, have positive and significant raw and CAPM-adjusted returns, with the best performance of portfolios formed on the banking sector. The effect of these three risks is also confirmed by the MR and GRS tests in both the gross and net approaches. We also observe the influence of political risk on the future returns (rejected MR and GRS tests' hypotheses), but in this case, the raw returns and market risk-adjusted returns sometimes significantly depart from 0. Finally, the currency risk proves the least important. We find no clear cross-sectional relationship between the currency risk and expected returns. ${ }^{13}$

\footnotetext{
${ }^{13}$ As an additional robustness check, we also apply a cross-sectional test in the spirit of Fama and MacBeth (1987), that was commonly employed in the earlier studies of country risk. The results are reported in Table A2 of the on-line appendix. Although the coefficients from the univariate regressions are statistically insignificant, they are positive and thus consistent with the results presented in Tables 1 and 3.
} 
Table 3 The Performance of Equal-Weighted Tertile Portfolios from Sorts on Five Components of Country Risk

\begin{tabular}{|c|c|c|c|c|c|c|c|c|c|c|c|c|}
\hline & \multicolumn{6}{|c|}{ Gross returns } & \multicolumn{6}{|c|}{ Net returns } \\
\hline & Low & Med. & High & $H-L$ & $M R$ & GRS & Low & Med. & High & $H-L$ & $M R$ & GRS \\
\hline \multicolumn{13}{|c|}{ Sovereign risk } \\
\hline \multirow[t]{2}{*}{ Mean } & 0.39 & 0.75 & $0.89^{\star \star}$ & $0.48^{\star \star}$ & 2.5 & & 0.34 & 0.68 & $0.88^{\star \star}$ & $0.53^{\star \star}$ & 0.4 & \\
\hline & $(1.08)$ & $(1.62)$ & (1.99) & $(2.10)$ & & & (0.94) & $(1.50)$ & -2.03 & $(2.28)$ & & \\
\hline Volatility & 5.39 & 6.02 & 6.05 & 3.20 & & & 5.47 & 5.86 & 5.98 & 3.16 & & \\
\hline SR & 0.25 & 0.43 & 0.51 & 0.52 & & & 0.21 & 0.40 & 0.51 & 0.58 & & \\
\hline \multirow[t]{2}{*}{$\alpha$ CAPM } & 0.13 & $0.47^{\star \star}$ & $0.63^{\star \star}$ & $0.49^{\star \star}$ & 1.3 & 5.4 & 0.15 & $0.48^{\star \star}$ & $0.70^{\star \star \star}$ & $0.53^{\star \star}$ & 0.3 & 2.0 \\
\hline & $(0.95)$ & $(2.36)$ & $(2.48)$ & $(2.17)$ & & & $(1.07)$ & $(2.55)$ & $(2.80)$ & $(2.42)$ & & \\
\hline \multirow[t]{2}{*}{$\alpha_{4 \mathrm{~F}}$} & 0.01 & 0.21 & 0.30 & 0.27 & 23.5 & 28.9 & 0.02 & $0.26^{\star}$ & $0.39^{\star \star}$ & 0.34 & 14.5 & 10.5 \\
\hline & $(0.08)$ & (1.33) & (1.57) & (1.31) & & & $(0.19)$ & $(1.68)$ & $(1.99)$ & (1.63) & & \\
\hline \multicolumn{13}{|c|}{ Currency risk } \\
\hline \multirow[t]{2}{*}{ Mean } & 0.49 & $0.82^{\star}$ & 0.71 & 0.23 & 52.1 & & 0.42 & $0.80^{\star}$ & 0.69 & 0.27 & 52.1 & \\
\hline & (1.29) & $(1.90)$ & (1.55) & $(1.02)$ & & & (1.11) & $(1.86)$ & (1.57) & $(1.26)$ & & \\
\hline Volatility & 5.41 & 5.66 & 6.37 & 3.18 & & & 5.48 & 5.56 & 6.19 & 2.99 & & \\
\hline SR & 0.32 & 0.50 & 0.39 & 0.25 & & & 0.26 & 0.50 & 0.39 & 0.31 & & \\
\hline \multirow[t]{2}{*}{$\alpha$ CAPM } & 0.23 & $0.56^{\star \star \star}$ & $0.44^{\star}$ & 0.22 & 55.3 & 2.9 & 0.23 & $0.62^{\star \star \star}$ & $0.50^{\star \star}$ & 0.27 & 54.3 & 0.9 \\
\hline & (1.58) & $(2.98)$ & (1.69) & $(0.98)$ & & & (1.55) & (3.38) & $(2.03)$ & $(1.27)$ & & \\
\hline \multirow[t]{2}{*}{$\alpha_{4 F}$} & 0.09 & $0.32^{\star \star}$ & 0.11 & 0.04 & 85.8 & 17.5 & 0.08 & $0.40^{\star \star \star}$ & 0.20 & 0.12 & 83.2 & 5.5 \\
\hline & $(0.61)$ & $(2.19)$ & $(0.57)$ & $(0.14)$ & & & $(0.57)$ & (2.68) & $(1.05)$ & (0.53) & & \\
\hline \multicolumn{13}{|c|}{ Banking sector risk } \\
\hline \multirow[t]{2}{*}{ Mean } & 0.35 & $0.78^{\star}$ & $0.90^{\star \star}$ & $0.54^{\star \star}$ & 3.0 & & 0.30 & $0.73^{\star}$ & $0.87^{\star \star}$ & $0.55^{\star \star}$ & 1.3 & \\
\hline & $(0.97)$ & $(1.74)$ & $(1.98)$ & $(2.38)$ & & & $(0.84)$ & $(1.65)$ & (1.98) & $(2.51)$ & & \\
\hline Volatility & 5.54 & 5.78 & 6.15 & 3.09 & & & 5.62 & 5.64 & 6.04 & 3.00 & & \\
\hline SR & 0.22 & 0.46 & 0.51 & 0.60 & & & 0.18 & 0.45 & 0.50 & 0.64 & & \\
\hline \multirow[t]{2}{*}{$\alpha \mathrm{CAPM}$} & 0.08 & $0.52^{\star \star}$ & $0.64^{\star \star \star}$ & $0.55^{\star \star}$ & 2.8 & 2.9 & 0.10 & $0.55^{\star \star \star}$ & $0.68^{\star \star \star}$ & $0.56^{\star \star \star}$ & 1.2 & 1.2 \\
\hline & $(0.62)$ & $(2.36)$ & $(2.58)$ & $(2.48)$ & & & $(0.77)$ & $(2.63)$ & $(2.87)$ & (2.65) & & \\
\hline \multirow[t]{2}{*}{$\alpha_{4 F}$} & -0.03 & 0.23 & $0.32^{\star}$ & 0.33 & 23.1 & 22.0 & 0.00 & $0.28^{\star}$ & $0.39^{\star \star}$ & $0.38^{\star}$ & 14.6 & 9.1 \\
\hline & $(-0.25)$ & (1.33) & $(1.72)$ & (1.64) & & & $(-0.07)$ & $(1.68)$ & $(2.12)$ & $(1.86)$ & & \\
\hline \multicolumn{13}{|c|}{ Political risk } \\
\hline \multirow[t]{2}{*}{ Mean } & 0.47 & 0.68 & $0.88^{\star \star}$ & 0.37 & 1.1 & & 0.42 & 0.62 & $0.86^{\star \star}$ & 0.39 & 0.9 & \\
\hline & $(1.20)$ & $(1.42)$ & $(2.14)$ & (1.61) & & & $(1.08)$ & $(1.31)$ & $(2.15)$ & (1.63) & & \\
\hline Volatility & 5.44 & 6.46 & 5.66 & 3.45 & & & 5.52 & 6.36 & 5.52 & 3.43 & & \\
\hline SR & 0.30 & 0.36 & 0.54 & 0.37 & & & 0.26 & 0.34 & 0.54 & 0.39 & & \\
\hline \multirow[t]{2}{*}{$\alpha$ CAPM } & 0.20 & $0.38^{\star}$ & $0.64^{\star \star \star}$ & 0.39 & 1.5 & 6.2 & 0.23 & $0.40^{\star \star}$ & $0.70^{\star \star \star}$ & $0.41^{*}$ & 1.0 & 3.1 \\
\hline & $(1.36)$ & $(1.80)$ & $(2.66)$ & (1.64) & & & $(1.50)$ & $(2.06)$ & $(2.91)$ & $(1.75)$ & & \\
\hline \multirow[t]{2}{*}{$\alpha_{4 F}$} & 0.11 & 0.06 & $0.35^{\star}$ & 0.20 & 37.1 & 23.5 & 0.13 & 0.12 & $0.41^{\star *}$ & 0.22 & 37.5 & 14.6 \\
\hline & $(0.83)$ & $(0.37)$ & $(1.76)$ & $(0.82)$ & & & $(1.04)$ & $(0.80)$ & $(2.05)$ & $(0.95)$ & & \\
\hline
\end{tabular}


Economic structure risk

\begin{tabular}{|c|c|c|c|c|c|c|c|c|c|c|c|c|}
\hline Mean & $\begin{array}{l}0.41 \\
(1.11)\end{array}$ & $\begin{array}{l}0.73 \\
(1.55)\end{array}$ & $\begin{array}{l}0.88^{\star *} \\
(2.03)\end{array}$ & $\begin{array}{c}0.43^{\star} \\
(1.90)\end{array}$ & 1.3 & & $\begin{array}{l}0.37 \\
(0.99)\end{array}$ & $\begin{array}{c}0.66 \\
(1.45)\end{array}$ & $\begin{array}{l}0.86^{\star \star} \\
(2.06)\end{array}$ & $\begin{array}{l}0.45^{\star \star} \\
(1.98)\end{array}$ & 0.4 & \\
\hline Volatility & 5.60 & 6.04 & 5.94 & 3.31 & & & 5.67 & 5.96 & 5.72 & 3.08 & & \\
\hline SR & 0.26 & 0.42 & 0.51 & 0.45 & & & 0.23 & 0.39 & 0.52 & 0.51 & & \\
\hline QCAPM & $\begin{array}{l}0.14 \\
(0.99)\end{array}$ & $\begin{array}{l}0.45^{\star \star} \\
(2.30)\end{array}$ & $\begin{array}{l}0.64^{\star \star} \\
(2.40)\end{array}$ & $\begin{array}{l}0.46^{\star \star} \\
(2.02)\end{array}$ & 0.5 & 3.8 & $\begin{array}{c}0.17 \\
(1.21)\end{array}$ & $\begin{array}{l}0.47^{\star \star} \\
(2.52)\end{array}$ & $\begin{array}{l}0.69^{\star \star \star} \\
(2.80)\end{array}$ & $\begin{array}{l}0.48^{\star *} \\
(2.28)\end{array}$ & 0.2 & 1.4 \\
\hline$\alpha_{4 F}$ & $\begin{array}{l}0.01 \\
(0.00)\end{array}$ & $\begin{array}{l}0.18 \\
(1.17)\end{array}$ & $\begin{array}{l}0.32 \\
(1.62)\end{array}$ & $\begin{array}{l}0.28 \\
(1.37)\end{array}$ & 10.5 & 22.3 & $\begin{array}{l}0.04 \\
(0.25)\end{array}$ & $\begin{array}{l}0.22 \\
(1.45)\end{array}$ & $\begin{array}{l}0.41^{\star *} \\
(2.10)\end{array}$ & $\begin{array}{l}0.32^{\star} \\
(1.67)\end{array}$ & 3.5 & 7.7 \\
\hline
\end{tabular}

Notes: The table presents the performance of equal-weighted tertile portfolios from sorts on five individual metrics of sovereign risk, currency risk, banking sector risk, political risk, and economic structure risk. $H$ $L$ is the zero-investment portfolio that includes a long position in the high-risk portfolios and a short position in the low-risk portfolios. Mean is the mean monthly excess return; Volatility is the standard deviation of monthly returns; $S R$ is the annualized Sharpe ratio; and $\alpha_{C A P M}$ and $\alpha_{4 F}$ are intercepts from the country-level CAPM and four-factor model, respectively. "Gross" and "net" approaches refer to whether adjustment is made for taxes on dividends (net approach) or not (gross approach). MR and GRS are $p$ values from the tests of monotonic relation by Patton and Timmerman (2010) and the GRS test (Gibbons et al., 1989), respectively. The means, volatilities, $p$-values, and intercepts are expressed in percentage terms. The numbers in brackets are $t$-statistics based on bootstrap standard errors, and values showing statistical significance at the $10 \%$ level are given in bold characters. Asterisks $\left({ }^{*},{ }^{* \star},{ }^{* *}\right)$ indicate values significantly different from zero at the $10 \%, 5 \%$, and $1 \%$ levels, respectively.

Interestingly, as for the aggregate country risk measure, in the case of nearly all individual risks, the abnormal returns are fully explained by the four-factor model. In other words, the country-level value, size, and momentum effects incorporate the country risks examined in this study.

Table 4 Pair-Wise Correlation Coefficients Between Returns on Zero-Investment Portfolios from Sorts on Country Risk Metrics

\begin{tabular}{|c|c|c|c|c|c|c|c|c|c|c|}
\hline & \multicolumn{5}{|c|}{ Correlation coefficients } & \multicolumn{5}{|c|}{ t-stats } \\
\hline & Sovereign & Currency & Banking & Political & Economic & Sovereigr & Currency & Banking & Political & Economic \\
\hline & \multicolumn{10}{|c|}{ Gross returns } \\
\hline Currency & 0.91 & & & & & 33.06 & & & & \\
\hline Banking & 0.87 & 0.89 & & & & 26.14 & 29.02 & & & \\
\hline Political & 0.77 & 0.69 & 0.78 & & & 19.42 & 16.04 & 19.91 & & \\
\hline Economic & 0.92 & 0.87 & 0.84 & 0.74 & & 35.05 & 26.15 & 23.80 & 17.85 & \\
\hline \multirow[t]{2}{*}{ Country } & 0.95 & 0.92 & 0.92 & 0.81 & 0.91 & 44.01 & 34.88 & 34.17 & 21.27 & 32.21 \\
\hline & \multicolumn{10}{|c|}{ Net returns } \\
\hline Currency & 0.92 & & & & & 33.21 & & & & \\
\hline Banking & 0.86 & 0.89 & & & & 25.50 & 28.66 & & & \\
\hline Political & 0.78 & 0.71 & 0.80 & & & 19.92 & 16.72 & 20.63 & & \\
\hline Economic & 0.92 & 0.87 & 0.84 & 0.74 & & 35.21 & 26.21 & 23.47 & 17.87 & \\
\hline Country & 0.95 & 0.93 & 0.92 & 0.82 & 0.90 & 44.44 & 35.97 & 33.88 & 22.36 & 30.72 \\
\hline
\end{tabular}

Notes: The table presents pair-wise Pearson's correlation coefficients between returns on equal-weighted tertile dollar-neutral portfolios formed on the EIU indicators of sovereign risk, currency risk, banking sector risk, political risk, economic structure risk, and composite country risk. "Gross" and "net" approaches refer to whether adjustment is made for taxes on dividends (net approach) or not (gross approach). 
Furthermore, the returns on the strategies based on various types of risks are strongly correlated (Table 4). This is hardly surprising, as seen in Table 2, as the particular risk rankings remain similar. In consequence, the correlation coefficients between returns on zero-portfolios from sorts on the various risk metrics range from 0.69 to 0.95 ( 0.71 to 0.95 ) in the gross-return (net-return) approach.

\subsection{Influence of Weighting Method, Country Set, and Study Period}

Being interested in the robustness of the risk-based strategies, and how efficiently they can be implemented by international investors, we investigate their robustness across time and various country groups. Figure 1 depicts the cumulative excess return on the equal-weighted zero-investment portfolio from sorts on country risk along with the performance of standard asset pricing factors related to the size, value, and momentum effects. The country risk portfolio historically performs the best, with the cumulative performance in years 1998 through 2015 approximately 60-100 percentage points above the other factor portfolios. Remarkably, all the cross-sectional strategies record their peak in cumulative returns in years 2006 through 2010 after which the performance markedly deteriorates and the strategies deliver negative returns. Further supporting evidence concerning the country-risk-based portfolios is presented in Table 5. The findings confirm the dramatic deterioration of the risk-based strategy during the last decade. In fact, regardless of the sample breakpoint, we observe the dollar-neutral portfolios from sorts on country risk outperform to a greater extent in the earlier part of the research period than in the later part- the mean returns in the later sub-periods approximate zero (no longer significantly positive). This observation may pose a significant challenge to the reliability of the examined strategy. Whether it is a random stretch of underperformance or a structural change that casts doubt on the validity of country selection risk-based strategy remains an open question. 


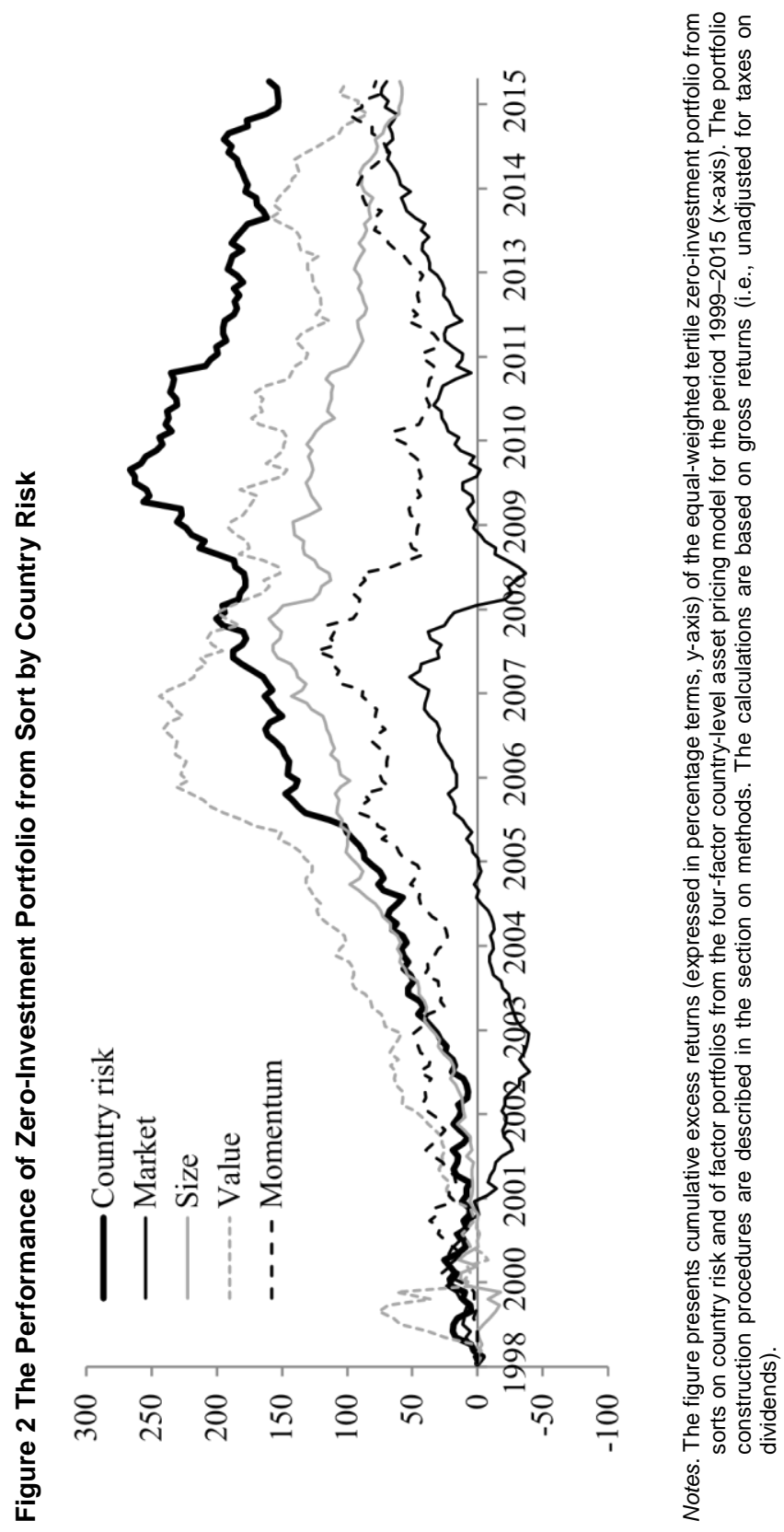

Finance a úvěr-Czech Journal of Economics and Finance, 68, 2018, no. 4 
Table 5 Returns on Zero-Investment Portfolios from Sorts on Country Risk in SubPeriods of the Full Sample

\begin{tabular}{|c|c|c|c|c|}
\hline & \multicolumn{2}{|c|}{ Gross returns } & \multicolumn{2}{|c|}{ Net returns } \\
\hline & Mean & $t$-stat & Mean & t-stat \\
\hline First half & $1.04^{\star \star \star}$ & (2.68) & $1.04^{\star \star \star}$ & (2.60) \\
\hline Second half & 0.03 & (0.13) & 0.13 & $(0.57)$ \\
\hline Pre-2007 peak & $0.99^{\star \star *}$ & (2.67) & $0.99^{\star \star \star}$ & (2.59) \\
\hline Post-2007 peak & 0.03 & $(0.10)$ & 0.13 & $(0.54)$ \\
\hline Pre-Lehman & $1.03^{\star \star \star}$ & (3.00) & $1.04^{\star \star \star}$ & (2.95) \\
\hline Post-Lehman & -0.15 & $(-0.56)$ & -0.05 & $(-0.21)$ \\
\hline Bull markets & 0.38 & (1.28) & 0.40 & (1.36) \\
\hline Bear markets & $0.74^{\star \star}$ & (2.04) & $0.82^{\star \star}$ & (2.22) \\
\hline
\end{tabular}

Notes: The table reports the mean returns on the zero-investment equal-weighted tertile portfolios formed on aggregate country risk within sub-periods of the full sample. The following cut-off points are used: the research period mid-point of March 31, 2007 (First half, Second half); the Dow-Jones peak on October 11, 2007 (Pre-2007 peak, Post-2007 peak); and the Lehman Brothers bankruptcy on September 16, 2008 (Pre-Lehman, Post-Lehman). Furthermore, the table presents the data categorized into bull and bear markets (i.e., in months of positive and negative market returns, correspondingly). The means are expressed in percentage terms. The numbers in brackets are $t$-statistics based on bootstrap standard errors, and values showing statistical significance at the $10 \%$ level are given in bold characters. Asterisks $\left({ }^{*},{ }^{* *},{ }^{* *}\right)$ indicate values significantly different from zero at the $10 \%, 5 \%$, and $1 \%$ levels, respectively. "Gross" and "net" approaches refer to whether adjustment is made for taxes on dividends (net approach) or not (gross approach).

The last two rows in Table 5 provide some further insight into the performance of the risk-based strategies. The gross (net) returns on the zero-investment portfolios averaged $0.74 \%(0.82 \%)$ monthly during bear markets and only $0.38 \%(0.40 \%)$ during bull markets. In other words, the tactical allocation proves, to some degree, countercyclical and provides some hedge against market distress.

Additional evidence on the distress-hedging properties of the country riskbased strategies is displayed in Table 6. The behavioral finance view on stock market inefficiencies points to irrationalities that cannot be easily arbitraged away (Jacobs, 2015). Thus, they may be predominantly pronounced in periods of elevated limits on arbitrage. The results presented in Panel A of Table 6 only partly confirm this hypothesis. Indeed, the returns are historically higher in periods of above-median term spread and expected volatility. However, the evidence on credit spreads is inconclusive, and is contradictory on the TED spread. The examined portfolios show worse performance when the market liquidity is tight than in the periods of low TED spread. 
Table 6 The Impact of Investor Sentiment and Limits on Arbitrage on the Performance of Zero-Investment Portfolios from Sorts on Country Risk

\begin{tabular}{|c|c|c|c|c|c|c|c|c|}
\hline & \multicolumn{4}{|c|}{ High readings } & \multicolumn{4}{|c|}{ Low readings } \\
\hline & \multicolumn{2}{|c|}{ Gross returns } & \multicolumn{2}{|c|}{ Net returns } & \multicolumn{2}{|c|}{ Gross returns } & \multicolumn{2}{|c|}{ Net returns } \\
\hline & Mean & $t$-stat & Mean & $t$-stat & Mean & $t$-stat & Mean & $t$-stat \\
\hline \multicolumn{9}{|c|}{ Panel A: limits on arbitrage } \\
\hline Volatility & 0.40 & $(1.06)$ & 0.49 & $(1.27)$ & $0.67^{\star \star}$ & (2.51) & $0.68^{\star \star}$ & (2.55) \\
\hline Term spread & 0.33 & (1.14) & 0.41 & (1.42) & $0.74^{\star \star}$ & (2.07) & $0.76^{\star \star}$ & (2.07) \\
\hline Credit spread & 0.50 & $(1.46)$ & $0.66^{\star \star}$ & (2.04) & $0.55^{\star}$ & $(1.86)$ & $0.55^{\star}$ & $(1.81)$ \\
\hline TED spread & $0.86^{\star \star}$ & (2.35) & $0.92^{\star \star}$ & (2.47) & 0.21 & $(0.76)$ & 0.24 & (0.89) \\
\hline \multicolumn{9}{|c|}{ Panel B: investor sentiment } \\
\hline BW & 0.35 & (0.85) & 0.37 & $(0.89)$ & $1.36^{\star \star \star}$ & (3.87) & $1.43^{\star \star \star}$ & (4.09) \\
\hline Sentix & $0.81^{\star \star *}$ & $(2.83)$ & $0.82^{\star \star \star}$ & $(2.85)$ & 0.27 & $(0.85)$ & 0.44 & (1.43) \\
\hline SSIC & $0.81^{\star *}$ & (2.24) & $0.80^{\star \star}$ & $(2.20)$ & 0.27 & $(1.07)$ & 0.38 & (1.53) \\
\hline PMI & 0.52 & (1.62) & $0.54^{\star}$ & (1.67) & $0.55^{\star}$ & (1.81) & $0.63^{\star \star}$ & (2.12) \\
\hline
\end{tabular}

Notes: The table reports the mean returns on the zero-investment equal-weighted tertile portfolios formed on aggregate country risk in months of above-median and below-median readings of indicators of marketwide limits on arbitrage and investor sentiment. The indicators include: TED spread-the difference between the 3-month U.S.\$ LIBOR rate and the yield on the U.S. benchmark 3-month treasury bills; Volatility - the VIX volatility index; Credit spread-BBB spreads of U.S. 10-year corporate bonds over 10year benchmark treasury bonds is the proxy for the credit risk; Term spread-difference between yields of 10- and 2-year benchmark U.S. treasury bonds, BW-Baker and Wurgler (2006) sentiment index, Sentix-Sentix Economic Indices Global Aggregate Overall Index; SSIC-State Street Global Markets Investor Confidence Index; PMLEconomy Weighted Manufacturing \& Non-Manufacturing Composite Purchasing Managers' Index. The means are expressed in percentage terms. The numbers in brackets are $t$-statistics based on bootstrap standard errors, and the significance at the $10 \%$ level is given in bold characters. Asterisks $\left({ }^{*},{ }^{* *},{ }^{* * *}\right)$ indicate values significantly different from zero at the $10 \%, 5 \%$, and $1 \%$ levels, respectively. "Gross" and "net" approaches refer to the adjustment for taxes on dividends.

Panel B of Table 6 presents the performance of the country selection strategy based on the risk in times of high or low investor sentiment. The results seem inconclusive and highly dependent on the choice of the particular sentiment indicator. Effectively, irrespective of the sentiment, the returns are, on average, non-negative (albeit not always significantly different from 0 ). Nonetheless, the performance is better during a month of high Sentix and SSIC readings and low BW readings. ${ }^{14}$

In Tables 7-9 we present alternative portfolio construction rules for the tactical asset allocation across countries based on their aggregate risk measure. To begin with, Table 7 displays the alternative breakpoints applied to the portfolio rankings (i.e., five quintile portfolios). Interestingly, although the GRS tests are still rejected, the crosssectional return and alpha patterns are materially non-monotonic, and none of the MR tests indicate monotonicity. The best performance is achieved not by the riskiest portfolio, but by the second riskiest quintile (quintile 4), which is also the only portfolio with a significant and positive mean abnormal return once the four-factor model is applied. In contrast, although the mean returns and intercepts on the riskiest portfolio are positive, they are predominantly insignificant and, in addition, the most volatile in

\footnotetext{
${ }^{14}$ One should bear in mind that the results are partially distorted by the fact that the BW index is available only until December, 2010, while the other sentiment measures are available for the entire study period.
} 
terms of standard deviation. In other words, investment in the riskiest quintile of stock markets seems to be no recipe for investment success.

Table 7 The Performance of Equal-Weighted Quintile Portfolios from Sorts on Country Risk

\begin{tabular}{|c|c|c|c|c|c|c|c|c|}
\hline & Low & 2 & 3 & 4 & High & $H-L$ & $M R$ & GRS \\
\hline \multicolumn{9}{|c|}{ Gross returns } \\
\hline \multirow[t]{2}{*}{ Mean } & 0.27 & $0.66^{\star}$ & 0.57 & $1.08^{\star \star}$ & 0.78 & $0.51^{\star}$ & 61.6 & \\
\hline & $(0.77)$ & (1.67) & (1.19) & (2.43) & $(1.60)$ & (1.87) & & \\
\hline Volatility & 5.65 & 5.54 & 6.20 & 5.74 & 6.93 & 3.99 & & \\
\hline Sharpe ratio & 0.17 & 0.41 & 0.32 & 0.65 & 0.39 & 0.44 & & \\
\hline \multirow[t]{2}{*}{ QCAPM } & -0.01 & $0.40^{\star *}$ & 0.30 & $0.85^{\star \star \star}$ & 0.49 & $0.50^{\star}$ & 72.4 & 1.4 \\
\hline & $(-0.08)$ & (2.16) & (1.24) & (3.21) & (1.58) & (1.76) & & \\
\hline \multirow[t]{2}{*}{$\alpha_{4 F}$} & -0.09 & 0.22 & 0.01 & $0.60^{\star \star \star}$ & 0.09 & 0.18 & 90.0 & 6.0 \\
\hline & $(-0.74)$ & (1.38) & $(-0.05)$ & (2.84) & (0.34) & $(0.67)$ & & \\
\hline \multicolumn{9}{|c|}{ Net returns } \\
\hline \multirow[t]{2}{*}{ Mean } & 0.17 & $0.65^{\star}$ & 0.57 & $0.97^{\star \star}$ & 0.74 & $0.56^{\star \star}$ & 44.6 & \\
\hline & $(0.53)$ & (1.65) & (1.18) & (2.27) & (1.61) & (2.09) & & \\
\hline Volatility & 5.76 & 5.56 & 6.09 & 5.51 & 6.70 & 3.81 & & \\
\hline Sharpe ratio & 0.10 & 0.40 & 0.32 & 0.61 & 0.38 & 0.51 & & \\
\hline \multirow[t]{2}{*}{ QCAPM } & -0.03 & $0.46^{\star *}$ & 0.37 & $0.80^{\star \star \star}$ & $0.55^{\star}$ & $0.56^{\star *}$ & 52.8 & 0.3 \\
\hline & $(-0.25)$ & (2.55) & $(1.61)$ & (3.34) & $(1.86)$ & $(2.06)$ & & \\
\hline \multirow[t]{2}{*}{$\alpha_{4 F}$} & -0.12 & $0.28^{\star}$ & 0.12 & $0.60^{\star \star \star}$ & 0.19 & 0.29 & 80.5 & 2.1 \\
\hline & $(-0.95)$ & (1.77) & $(0.54)$ & (2.98) & $(0.75)$ & (1.07) & & \\
\hline
\end{tabular}

Notes: The table presents the performance of equal-weighted quintile portfolios from sorts on composite country risk. $H-L$ is the zero-investment portfolio that includes a long position in the high-risk portfolio and a short position in the low-risk portfolio. Mean is the mean monthly excess return; Volatility is the standard deviation of monthly returns; $S R$ is the annualized Sharpe ratio; and $\alpha_{C A P M}$ and $\alpha_{4 F}$ are intercepts from the country-level CAPM and four-factor model, respectively. "Gross" and "net" approaches refer to whether adjustment is made for taxes on dividends (net approach) or not (gross approach). MR and GRS are $p$ values from the tests of monotonic relation by Patton and Timmerman (2010) and the GRS test (Gibbons et al., 1989), respectively. The means, volatilities, $p$-values, and intercepts are expressed in percentage terms. The numbers in brackets are $t$-statistics based on bootstrap standard errors, and values showing statistical significance at the $10 \%$ level are given in bold type. Asterisks $\left({ }^{*},{ }^{* *},{ }^{* * *}\right)$ indicate values significantly different from zero at the $10 \%, 5 \%$, and $1 \%$ levels, respectively.

The effectiveness of the risk-based country selection strategy is also seriously impeded by using alternative weighting schemes (i.e., other than equal-weighting). Table 8 reports the performance of capitalization-weighted and liquidity-weighted portfolios from sorts on aggregate country risk. The results are unimpressive. First, none of the zero-investment portfolios show positive and significant raw or riskadjusted returns. The mean gross (net) returns on the dollar-neutral capitalizationweighted portfolio are as low as $0.19 \%(0.29 \%)$ monthly. Second, none of the GRS tests' hypotheses are rejected. Third, with the sole exception of the raw returns on the liquidity-weighted portfolios, no monotonic pattern is detected. In summary, alternative weightings seem to pose a significant challenge to the risk-based strategies. 
When the portfolios are weighted based on either capitalization or liquidity, the country asset allocation based on country risk loses its effectiveness.

Table 8 The Performance of Capitalization-Weighted and Liquidity-Weighted Tertile Portfolios from Sorts on Country Risk

\begin{tabular}{|c|c|c|c|c|c|c|c|c|c|c|c|c|}
\hline & \multicolumn{6}{|c|}{ Gross returns } & \multicolumn{6}{|c|}{ Net returns } \\
\hline & Low & Med. & High & $H-L$ & $M R$ & GRS & Low & Med. & High & $H-L$ & $M R$ & GRS \\
\hline \multicolumn{13}{|c|}{ Capitalization-weighted portfolios } \\
\hline \multirow[t]{2}{*}{ Mean } & 0.46 & 0.59 & 0.56 & 0.19 & 27.2 & & 0.38 & 0.53 & 0.59 & 0.29 & 14.2 & \\
\hline & (1.31) & (1.29) & $(1.04)$ & $(0.67)$ & & & (1.09) & (1.19) & (1.10) & $(0.96)$ & & \\
\hline Volatility & 4.93 & 6.30 & 8.46 & 5.39 & & & 5.00 & 6.27 & 8.20 & 5.08 & & \\
\hline SR & 0.32 & 0.32 & 0.23 & 0.12 & & & 0.26 & 0.29 & 0.25 & 0.20 & & \\
\hline \multirow[t]{2}{*}{ QCAPM } & $0.22^{*}$ & 0.30 & 0.20 & 0.08 & 50.3 & 28.6 & 0.20 & 0.33 & 0.34 & 0.22 & 26.9 & 27.2 \\
\hline & (1.71) & $(1.42)$ & $(0.56)$ & $(0.23)$ & & & (1.59) & (1.57) & (1.01) & $(0.68)$ & & \\
\hline \multirow[t]{2}{*}{$\alpha_{4 F}$} & 0.13 & 0.00 & -0.23 & -0.26 & 83.7 & 58.5 & 0.12 & 0.05 & -0.06 & -0.09 & 71.2 & 76.2 \\
\hline & $(1.02)$ & $(-0.09)$ & $(-0.79)$ & $(-0.83)$ & & & $(0.89)$ & $(0.22)$ & $(-0.25)$ & $(-0.31)$ & & \\
\hline \multicolumn{13}{|c|}{ Liquidity-weighted portfolios } \\
\hline \multirow[t]{2}{*}{ Mean } & 0.40 & 0.54 & 0.74 & 0.44 & 6.8 & & 0.33 & 0.48 & 0.72 & 0.49 & 5.9 & \\
\hline & $(1.16)$ & $(1.21)$ & $(1.25)$ & $(1.25)$ & & & $(0.97)$ & $(1.08)$ & $(1.22)$ & (1.39) & & \\
\hline Volatility & 5.00 & 6.73 & 8.71 & 5.46 & & & 5.07 & 6.72 & 8.75 & 5.48 & & \\
\hline SR & 0.28 & 0.28 & 0.29 & 0.28 & & & 0.23 & 0.25 & 0.29 & 0.31 & & \\
\hline \multirow[t]{2}{*}{$\alpha C A P M$} & 0.16 & 0.23 & 0.38 & 0.32 & 19.6 & 52.0 & 0.16 & 0.25 & 0.47 & 0.41 & 13.3 & 44.6 \\
\hline & $(1.20)$ & (1.08) & $(0.92)$ & (0.93) & & & $(1.16)$ & (1.19) & (1.14) & (1.18) & & \\
\hline \multirow[t]{2}{*}{$\alpha_{4 F}$} & 0.06 & 0.03 & 0.08 & 0.13 & 45.7 & 97.2 & 0.05 & 0.07 & 0.19 & 0.24 & 34.9 & 93.1 \\
\hline & (0.38) & $(0.11)$ & $(0.15)$ & $(0.37)$ & & & $(0.35)$ & $(0.28)$ & $(0.43)$ & $(0.67)$ & & \\
\hline
\end{tabular}

Notes: The table presents the performance of capitalization- and liquidity-weighted tertile portfolios from sorts on composite country risk. The proxies for capitalization and liquidity are the total capitalization of all companies in an index, and the total turnover (expressed in USD) on all stocks in an index in months $t$ 12 to $t-1$, respectively. $H-L$ is the zero-investment portfolio that includes a long position in the high-risk portfolio and a short position in the low-risk portfolio. Mean is the mean monthly excess return; Volatility is the standard deviation of monthly returns; $S R$ is the annualized Sharpe ratio; and $\alpha_{C A P M}$ and $\alpha_{4 F}$ are intercepts from the country-level CAPM and four-factor model, respectively. "Gross" and "net" approaches refer to whether adjustment is made for taxes on dividends (net approach) or not (gross approach). MR and GRS are $p$-values from the tests of monotonic relation by Patton and Timmerman (2010) and the GRS test (Gibbons et al., 1989), respectively. The means, volatilities, $p$-values, and intercepts are expressed in percentage terms. The numbers in brackets are $t$-statistics based on bootstrap standard errors, and values showing statistical significance at the $10 \%$ level are given in bold type. Asterisks $\left({ }^{*},{ }^{* *}\right.$, $\left.{ }^{* * *}\right)$ indicate values significantly different from zero at the $10 \%, 5 \%$, and $1 \%$ levels, respectively.

Finally, not only the changes in weighting methodology challenge the effectiveness of the risk-based strategy. Table 9 displays the performance of the zeroportfolios from sorts on country risk within several subgroups of the main sample. Strikingly, in nearly all cases, none of the raw or risk-adjusted returns are significantly positive, and no cross-sectional pattern is detected by the MR or GRS tests. This is especially significant as each subsample includes data from over 30 distinct countries. The observations in Table 9 suggest that a successful application of tactical asset allocation based on country risk demands access to a very broad range of international 
markets to provide sufficient variation in stock returns. Furthermore, bearing in mind the evidence from Table 8 , an investor must be able to allocate equal parts of the portfolio even to the least liquid markets. These findings markedly undermine the applicability of the risk-based strategies and cast doubt on their profitability.

Table 9 The Performance of Zero-Investment Portfolios from Double Sorts on Country Risk and Market Characteristics

\begin{tabular}{|c|c|c|c|c|c|c|c|c|c|c|c|}
\hline & \multicolumn{3}{|c|}{ Raw returns } & \multicolumn{4}{|c|}{ CAPM } & \multicolumn{4}{|c|}{ Four-factor model } \\
\hline & $R$ & $t$-stat & $M R$ & $R$ & t-stat & $M R$ & GRS & $R$ & $t$-stat & $M R$ & GRS \\
\hline \multicolumn{12}{|c|}{ Gross returns } \\
\hline Large & 0.30 & 1.00 & 20.8 & 0.24 & 0.85 & 37.6 & 27.9 & -0.02 & -0.18 & 74.5 & 80.3 \\
\hline Small & 0.16 & 0.57 & 18.9 & 0.13 & 0.30 & 28.4 & 57.1 & -0.21 & -0.57 & 71.6 & 87.6 \\
\hline Liquid & $0.49^{\star}$ & 1.72 & 1.1 & 0.41 & 1.40 & 6.3 & 29.1 & 0.07 & 0.19 & 61.0 & 80.4 \\
\hline Illiquid & 0.18 & 0.65 & 49.3 & 0.07 & 0.16 & 64.2 & 42.2 & -0.26 & -0.76 & 86.7 & 62.2 \\
\hline Developed & 0.11 & 0.58 & 48.1 & 0.12 & 0.00 & 37.7 & 23.7 & -0.04 & -0.27 & 49.6 & 16.3 \\
\hline Emerging & -0.04 & 0.00 & 66.1 & -0.09 & -0.22 & 72.6 & 44.3 & -0.22 & -0.63 & 87.1 & 58.7 \\
\hline Open & 0.22 & 0.68 & 62.8 & 0.17 & 0.42 & 74.5 & 9.0 & -0.22 & -0.76 & 91.3 & 38.3 \\
\hline Closed & 0.36 & 0.85 & 12.8 & 0.33 & 0.85 & 17.3 & 45.1 & 0.24 & 0.68 & 34.5 & 86.7 \\
\hline Value & -0.02 & 0.03 & 94.2 & -0.11 & -0.31 & 96.9 & 9.8 & -0.43 & -1.22 & 98.9 & 11.0 \\
\hline Growth & 0.25 & 0.53 & 27.7 & 0.18 & 0.48 & 39.4 & 13.8 & 0.12 & 0.33 & 29.9 & 74.4 \\
\hline Up & 0.29 & 0.74 & 20.5 & 0.26 & 0.68 & 24.4 & 15.8 & 0.05 & 0.10 & 49.1 & 64.0 \\
\hline Down & -0.15 & -0.22 & 54.3 & -0.21 & -0.44 & 67.1 & 78.4 & -0.28 & -0.67 & 65.6 & 86.2 \\
\hline \multicolumn{12}{|c|}{ Net returns } \\
\hline Large & 0.40 & 1.32 & 20.5 & 0.36 & 1.29 & 31.8 & 21.9 & 0.14 & 0.44 & 62.6 & 69.9 \\
\hline Small & 0.17 & 0.57 & 41.8 & 0.15 & 0.34 & 49.3 & 27.4 & -0.17 & -0.45 & 80.9 & 74.0 \\
\hline Liquid & $0.60^{\star *}$ & 2.09 & 0.7 & $0.56^{*}$ & 1.84 & 3.6 & 22.4 & 0.26 & 0.83 & 41.9 & 72.3 \\
\hline Illiquid & 0.08 & 0.42 & 39.8 & 0.00 & -0.01 & 51.0 & 41.3 & -0.32 & -0.92 & 77.2 & 65.0 \\
\hline Developed & 0.30 & 1.34 & 5.6 & 0.31 & 0.00 & 2.6 & 18.8 & 0.18 & 0.00 & 11.4 & 51.7 \\
\hline Emerging & -0.03 & 0.04 & 69.7 & -0.06 & -0.15 & 73.4 & 30.3 & -0.24 & 0.00 & 91.5 & 45.9 \\
\hline Open & 0.49 & 1.46 & 27.0 & 0.48 & 1.29 & 33.4 & 6.9 & 0.12 & 0.28 & 71.3 & 40.1 \\
\hline Closed & 0.33 & 0.77 & 16.1 & 0.31 & 0.81 & 19.1 & 43.2 & 0.24 & 0.68 & 32.8 & 84.2 \\
\hline Value & -0.08 & -0.17 & 95.5 & -0.13 & -0.36 & 97.1 & 6.5 & -0.42 & -1.19 & 98.9 & 9.1 \\
\hline Growth & 0.37 & 0.83 & 14.8 & 0.33 & 0.89 & 20.1 & 15.0 & 0.30 & 0.89 & 13.7 & 61.8 \\
\hline Up & 0.47 & 1.16 & 10.2 & 0.45 & 1.20 & 11.0 & 21.2 & 0.28 & 0.78 & 31.2 & 50.6 \\
\hline Down & -0.16 & -0.27 & 46.4 & -0.19 & -0.43 & 53.5 & 54.7 & -0.33 & -0.83 & 68.4 & 68.7 \\
\hline
\end{tabular}

Notes: The table presents the performance of capitalization-weighted zero-investment portfolios from double sorts on country risk and additional characteristics: size, liquidity, development, openness, B/M ratio, and past returns. The markets are first sorted on the additional characteristics, then the country-risk based equal-weighted tertile portfolios are formed within the above-median and below-median subgroups. The zero-investment portfolios include a long position in the high-risk portfolio and a short position in the lowrisk portfolio, within the respective subgroups. $R$ is the mean monthly excess return, $\alpha$ is the intercept from an asset pricing model, and $t$-stat is the corresponding $t$-statistic. "Gross" and "net" approaches refer to whether adjustment is made for taxes on dividends (net approach) or not (gross approach). MR and GRS are $p$-values from the tests of monotonic relation by Patton and Timmerman (2010) and the GRS test (Gibbons et al., 1989), respectively. The means, $p$-values, and intercepts are expressed in percentage terms. Values showing statistical significance at the $10 \%$ level are given in bold type. Asterisks $\left({ }^{*},{ }^{* \star}\right)$ indicate values significantly different from zero at the $10 \%$ and $5 \%$ levels, respectively. 


\section{Concluding Remarks}

The study presented in this paper examines the efficiency of tactical asset allocation strategies based on country risk measures associated with sovereign debt, banking sector, currency, economic structure, and political risks. We find the country risk to be priced into the global equity markets. In the years 1999-2015, the equalweighted portfolios of the riskiest countries outperformed the safest countries by approximately $0.50 \%$ monthly. This atypical performance is explained by the fourfactor asset pricing model which accounts for cross-country size, value, and momentum effects. The risk-return relationships are driven mostly by the risks associated with sovereign debt, economic structure, and the banking sector, whereas the currency risk displays no significant association with future returns.

Nonetheless, the risk-based strategies lack robustness and lose in the confrontation with numerous real-life problems faced by individual and institutional investors. First, these strategies work only for equal-weighted portfolios, and thus, require allocation of considerable parts of the portfolio to small and illiquid markets. For the capitalization-weighted and liquidity-weighted portfolios, the abnormal returns are no longer significant. Second, the returns on the zero-investment portfolios from sorts on risk are unprofitable within a smaller subset of countries (e.g., within only the developed or liquid markets). This would pose a further challenge for the use of economic content of country risk for investment practice. Finally, the performance of the examined strategies significantly deteriorates in recent years. In fact, in after the global financial crisis, the zero-investment portfolios formed on risk display negative returns.

This paper yields lessons for asset allocators, individual investors, fund pickers and portfolio managers with a global investment mandate. It shows that the countryspecific country risks relate to future returns. The application of the knowledge to investment practice may, however, pose significant challenges. Our paper provides new insights into country-level asset pricing that could be employed in a crosssectional asset pricing model for assessing investment performance or determining the cost of capital.

Further research on these issues could be pursued in several directions. First, one limitation of this study is the nonexistent accounting for transaction costs and cross-country capital mobility constraints. Considering these issues could yield some further insights into the real-life aspects of risk-based strategies. Second, it would be valuable to extract the detailed components of the sovereign or banking sector risks which are the most important for future returns. This information could help to further optimize the country-level asset allocation processes. Third, our framework could be easily replicated for other asset classes, for example, real estate (via REITs) or sovereign bonds. Finally, examining the effect of risk within and across further asset classes could also help in the design of better-performing strategies. 


\section{REFERENCES}

Andrade SC (2009): A Model of Asset Pricing under Country Risk. Journal of International Money and Finance, 28(4):671-695.

Angelidis T, Tessaromatis N (2014): Global Style Portfolios Based on Country Indices. Bankers, Markets \& Investors, forthcoming. Retrieved from: http://mpra.ub.uni-muenchen.de/53094.

Asness CS, Liew JM, Stevens RL (1997): Parallels Between the Cross-Sectional Predictability of Stock and Country Returns. Journal of Portfolio Management, 23:79-87.

Asness CS, Moskowitz TJ, Pedersen LH (2013): Value and Momentum Everywhere. Journal of Finance, 68:929-985.

Baker M, Wurgler J (2006): Investor Sentiment and the Cross-Section of Stock Returns. Journal of Finance, 61:1645-1680.

Bali C, Cakici N, Fabozzi F. (2013): Book-to-Market and the Cross-Section of Expected Stock Returns in International Stock Markets. Journal of Portfolio Management, 39:101-115.

Balvers R, Wu Y (2006): Momentum and Mean Reversion across National Equity Markets. Journal of Empirical Finance, 13:24-48.

Bekaert G, Erb CB, Harvey CR, Viskanta (1996): The Cross-Sectional Determinants of Emerging Equity Market Returns. Retrieved from

https://www0.gsb.columbia.edu/faculty/gbekaert/PDF_Papers/The_cross-sectional_determinants.pdf (accessed 21 September 2015).

Bekaert G, Harvey C, Lundblad C (2007): Liquidity and expected returns: Lessons from emerging markets. Review of Financial Studies, 20:, 1783-1831.

Bhojraj S, Swaminathan B (2006): Macromomentum: Returns Predictability in International Equity Indices. Journal of Business, 79:429-451.

Brown A, Du DY, Rhee SG, Zhang L. (2008): The Returns to Value and Momentum in Asian Markets. Emerging Markets Review, 9:79-88.

Carhart MM (1997): On Persistence in Mutual Fund Performance. Journal of Finance, 52:57-82.

Chinn MD, Ito H (2008): A New Measure of Financial Openness. Journal of Comparative Policy Analysis, 10:309-322.

Cochrane JH (2005): Asset Pricing. Princeton: Princeton University Press.

Dahlquist M, Bansal R (2002): Expropriation Risk and Return in Global Equity Markets. EFA 2002 Berlin Meetings Presented Paper. Available at SSRN: http://dx.doi.org/10.2139/ssrn.298180 (accessed 21 September 2015).

de Moor L, Sercu P (2013): The Smallest Stocks Are Not Just Smaller: Global Evidence. European Journal of Finance, 21(2):51-70.

Desrosiers S, L'Her J-F, Plante J-F (2004): Style Management in Equity Country Allocation. Financial Analyst Journal, 60:40-54.

Dimic N, Orlov V, Piljak V (2015): The Political Risk Factor in Emerging, Frontier, and Developed Stock Markets. Finance Research Letters, 15:239-245.

EIU (2015a): Country Risk Service. The Economist Intelligence Unit. Retrieved from: https://www.eiu.com/handlers/PublicDownload.ashx?mode=m\&fi=risk-section/country-riskservice.pdf (accessed 20 September 2015):

EIU (2015b): Country Risk Model. The Economist Intelligence Unit. Retrieved from: https://www.eiu.com/handlers/PublicDownload.ashx?mode=m\&fi=risk-section/country-riskmodel.pdf (accessed 20 September 2015).

Erb CB, Harvey CR, Viskanta TE (1995): Country Credit Risk and Global Portfolio Selection. Journal of Portfolio Management, 21(2):74-83.

Erb CB, Harvey CR, Viskanta TE (1996): Political Risk, Economic Risk, and Financial Risk. Financial Analyst Journal, 52(6):29-46. 
Fama EF, French KR (2012): Size, Value, and Momentum in International Stock Returns. Journal of Financial Economics, 105(3):457-472.

Fama, EF, MacBeth, JD (1973): Risk, Return, Equilibrium: Empirical Tests. Journal of Political Economy, 81(3):607-636.

Ferson WE, Harvey CR (1994): Sources of Risk and Expected Returns in Global Equity Markets. Journal of Banking and Finance, 18:775-803.

Gibbons MR, Ross SA, Shanken J (1989): A Test of the Efficiency of a Given Portfolio. Econometrica, 57(5):1121-1152.

Harvey CR (2004): Country Risk Components, the Cost of Capital, and Returns in Emerging Markets. Wilkin S (ed.): Country and Political Risk: Practical Insights for Global Finance. Risk Books, London, 71-102. Available at SSRN: http://dx.doi.org/10.2139/ssrn.620710 (accessed 21 September 2015).

Hoti S, McAleer (2002): Country Risk Ratings: An International Comparison. Working paper, Department of Economics University of Western Australia. Retrieved from: https://faculty.fuqua.duke.edu/ charvey/Teaching/CDROM_BA456_2003/Country_risk_ratings.pdf (accessed 18 September 2015).

Hoti S, McAleer (2005): Modeling the Riskiness in Country Risk Ratings. Emerald Publishing Group: Bingley.

Jacobs H (2015): What Explains the Dynamics of 100 Anomalies? Journal of Banking \& Finance, 57:65-85.

Keppler M, Encinosa P (2011): The Small-Country Effect Revisited. Journal of Investing, 20:99-103.

Keppler M, Traub H (1993): The Small-Country Effect: Small Markets Beat Large Markets. Journal of Investing, 2:17-24.

Kim D (2012): Value Premium Across Countries. Journal of Portfolio Management, 38:75-86.

Liew J, Vassalou M (2000): Can Book-to-Market, Size and Momentum Be Risk Factors that Pedict Economic Growth? Journal of Financial Economics, 57:221-245.

Macedo R (1995): Value, Relative Strength and Volatility in Global Country Selection. Financial Analyst Journal, 51(2):70-78.

Malin M, Bornholt G (2013): Long-Term Return Reversal: Evidence from International Market Indices. Journal of International Financial Markets, Institutions and Money, 25:1-17.

MSCI (2014a): MSCI Global market accessibility review. Retrieved from: http://www.msci.com/resources/products/indexes/global_equity_indexes/gimi/stdindex/MSCI_Glob al_Market_Accessibiliy_Review_June2014.pdf.

MSCI (2014b): MSCI global investable market indexes methodology. Retrieved from: http://www.msci.com/eqb/methodology/meth_docs/MSCI_Aug14_GIMIMethod.pdf.

Newey WK, West KD (1987): A Simple Positive-Definite Heteroskedasticity and Autocorrelation Consistent Covariance matrix. Econometrica, 55:703-708.

Patton AJ, Timmermann A (2010): Monotonicity in Asset Returns, New Tests with Applications to the Term Structure, the CAPM and Portfolio Sorts. Journal of Financial Economics, 98: 605-625.

Sharpe WF (1964): Capital Asset Prices: A Theory of Market Equilibrium Under Conditions of Risk. Journal of Finance, 19:425-442.

Umutlu M (2015): Idiosyncratic Volatility and Expected Return at the Global Level. Financial Analyst Journal, 71(6):58-71.

Willenbrock S (2011): Diversification Return, Portfolio Rebalancing, and the Commodity Return Puzzle. Financial Analyst Journal, 67:42-49.

Zaremba A (2015a): Is There a Low-Risk Anomaly Across Countries? Eurasian Economic Review, 6(1):45-65. 
Zaremba A (2015b): Country Selection Strategies Based on Value, Size and Momentum. Investment Analyst Journal, 44(3):171-198.

Zaremba A (2015c): Country Selection Strategies Based on Quality. Managerial Finance, 41(12):1336-1356. 